\title{
A CONCEPÇÃO DE NATUREZA NA GEOGRAFIA E A RELAÇÃO COM A EDUCAÇÃO AMBIENTAL
}

\author{
THE CONCEPT OF NATURE IN GEOGRAPHY AND THE RELATIONSHIP WITH \\ ENVIRONMENTAL EDUCATION
}

\section{LA CONCEPCIÓN DE LA NATURALEZA EN LA GEOGRAFIA Y EDUCACIÓN AMBIENTAL}

\author{
BISPO, Marcileia Oliveira ${ }^{1}$
}

\begin{abstract}
RESUMO: A geografia, desde sua origem, sempre teve como uma de suas características a relação entre o ser humano e o meio ambiente, mesmo na Antiguidade, quando era meramente descritiva e os diversos povos (egípcios, romano, árabes, entre outros) desenvolveram um conhecimento geográfico próprio e independente. A relação entre o ser humano e o meio ambiente tem passando por diversas transformações no período histórico, produzindo novas formulações em suas bases teóricas. Nesta perspectiva é extremamente importante conhecer os significados da concepção de natureza no decorrer da história humana, pois tal conhecimento é fundamental para entendermos o ambiente e compreendermos a temática ambiental atual. Pretendemos assim, neste artigo, evidenciar os diversos conceitos de natureza na ciência geográfica através da evolução de seu pensamento nos diferentes momentos históricos, refletir o embate da modernidade e pós-modernidade e a questão ambiental e por fim explicitar a relação da Geografia para com a educação ambiental. Para tal abordagem damos um recorte temporal a partir da institucionalização da geografia no campo do conhecimento científico, ou seja, final do século XX.
\end{abstract}

Palavras-chave: Natureza; Educação Ambiental; Geografia

RESUMEM: La Geografia, desde su origen, siempre tuve como una de suyas características la relacción entre el ser humano y el medio ambiente, mismo en la Antiguedad, cuando iba meramente descritiva e los diversos pueblos (egípcios, romanos, árabes, y otros) desenvolvieron un conocimiento geográfico próprio y independiente. La relación del ser humano con el medio ambiente ha pasado por diversas transformaciones en los períodos históricos, producindo nuevas formulaciones en sus buscas teóricas. En esta perspectiva es

\footnotetext{
${ }^{1}$ Possui Graduação em Geografia pela Universidade do Tocantins (1996) e Mestrado e Doutorado em Geografia pelo Instituto de Estudos Socio Ambientais IESA/UFG. Atualmente é professora na Universidade federal do Tocantins e no Colégio Estadual de Cristalândia. Membro de Conselho editorial da revista Produção Acadêmica e do Núcleo de estudos NURBA/UFT e do laboratório LEGEO/UFT. .Tem experiência na área de Geografia, com ênfase em Educação Ambiental, atuando principalmente nos seguintes temas: educação ambiental, educação ambiental, professores, meio ambiente e representações. marcileiabispo@hotmail.com
} 
importante conocer los significados de la concepción de naturaleza en el transcurrir de la historía humana, pues tal conocimiento es fundamental para entendermos el ambiente y comprendermos la temática ambiental atual. Así, queremos en éste artículo, evidenciar los diversos conceptos de la naturaleza en la ciência geográfica por meio de la evolución de su pensamiento en los diferentes momentos históricos, reflectir el embate de la modernidad y pós-modernidad y la questión ambiental y finalmente explicitar la relacción de la Geografia con la educación ambiental. En esta abordagen utilizamos como recorte temporal la institucionalizacción de la Geografia en el campo del conocimiento científico, o sea, el fin del siglo XX.

Palabras clave: Naturaleza; Educación Ambiental; Geografía

ABSTRACT: The geography, since its origin, always had as one of its characteristics the relation between the human and the environment, even in antiquity, when it was merely descriptive and different peoples (Egyptian, Roman, Arab, etc.) developed a geographic knowledge own and independent. The relation between the human and the environment has experienced several transformations in the historical period, producing new formulations of its theoretical bases. This perspective is extremely important to know the meanings of nature in the course of human history, because such knowledge is essential to understanding the environment and understand the current environmental subject matter current. We thus intend in this article, to show the different concepts of nature in geographical science through the evolution of his thinking in different historical moments, to reflect the clash of modernity and postmodernity and the environmental question and finally explicit the relation of geography to education environment. For this approach we give a time frame from the institutionalization of geography in the field of scientific knowledge, in other word the late twentieth century.

Key ords: Nature, Environmental Education, Geography

\section{INTRODUÇÃO}

Segundo Claval (2002, p. 11) "duas grandes concepções de geografia foram imaginadas entre o final do século XVIII e os anos 70”, a primeira de caráter naturalista que insistia nas relações entre sociedade e natureza e a segunda de caráter funcionalista que preocupava-se com o papel do espaço no funcionamento dos grupos humanos. As bases metodológicas que tais concepções utilizaram para construir o conhecimento foram criticadas, fazendo emergir nova reflexão epistemológica.

Essa reflexão epistemológica reorienta novas formas de procedimento no âmbito da ciência geográfica e permite a construção de novos saberes, desperta um olhar diferenciado 
para o ambiente e assim o crescente desenvolvimento dos estudos da questão ambiental na geografia. Assinalamos que as teorias ou correntes filosóficas não se encerram quando uma nova teoria ou corrente é pensada, mas coexistem. Assim ocorre com a Ciência Geográfica.

E a educação ambiental precisa contar com novos instrumentos, em sua implementação que é interdisciplinar e que pode ir além alcançando a transdisciplinaridade. Essa discussão necessita passar pela formação de um novo homem, numa perspectiva qualitativa e numa relação respeito.

Neste sentido, o objetivo deste trabalho foi apresentar o conceito de natureza na geografia, a questão ambiental no embate da modernidade e pos-modernidade e a relação com a Geografia.

\section{A NATUREZA E A GEOGRAFIA CLÁSSICA ${ }^{2}$}

A institucionalização da Geografia enquanto ciência acadêmica no campo do conhecimento científico, ocorre nas universidades européias (inicialmente na França e na Alemanha) no final do século XIX, provocando rupturas com formas de conceber o conhecimento da época que privilegiava uma visão de um mundo empirista, teleológica e metafísica. A partir dessa ruptura surge a Geografia moderna que Capel (1981, p. 248) aponta: "El nascimento de la geografia como ciência moderna se realiza precisamente trás la ultima ruptura epistemológica em el marco de la episteme contemporânea", aponta ainda que a institucionalização universitária da geografia se desenvolve em torno de dois problemas chaves: o primeiro é o estudo da diferenciação espacial na superfície terrestre e o segundo é o estudo da relação homem-meio.

Essa ruptura com o conhecimento precedente não é exclusivo da Geografia, já que ele ocorre também no interior das outras ciências e é anterior ao surgimento da geografia moderna, "o novo racionalismo e a ciência moderna nascem no Século das Luzes, e nada é mais imediato que a associação da modernidade aos filósofos do século XVII" (GOMES, 2000).

A ciência moderna tem como base teórica o positivismo, entendido como método científico cuja concepção de mundo é impirista, indutivo e racionalista, parte da observação, e mediante a classificação e comparação chega à formulação de conclusões gerais, de caráter objetivo e progressista. A Geografia nesta perspectiva positivista herda, segundo Madruga

\footnotetext{
${ }^{2}$ Andrade, M. C. (1999), explicita que a Geografia Clássica também é conhecida como Tradicional, e nos meados de 1940 foi chamada de Científica.
} 
(1986, p.91) “a definição de que é uma ciência que se fundamenta na observação, de que é uma ciência de síntese e que sua existência depende de princípios (leis) como: unidade terrestre, individualidade dos lugares, da atividade, da conexão, da comparação, da extensão e localização".

Assim, a relação homem-meio e as significações do conceito de natureza na geografia clássica serão pautados num saber sistemático, onde o conceito de geografia é tido no sentido do palpável e do concreto.

No desenvolvimento dessa corrente geográfica tivemos duas tendências que influenciaram toda uma forma de pensar - o Determinismo e o Possibilismo. A tendência de base determinista tem como expoentes Alexander Von Humboldt e Karl Ritter. O primeiro concebia a Geografia como ciência de síntese, tendo o papel de sistematizar todos os conhecimentos relativos à natureza, "com Humboldt ganha forma acadêmica e escolar a geografia-ecologia, isto é, a concepção de mundo como unidade cósmica, que envolve o próprio homem" (MOREIRA, 1982). Para Ritter caberia a geografia o papel de explicar a natureza e seus sistemas, "há para Ritter, uma teleologia na natureza, isto é, ela existe com finalidade de servir ao homem" (MOREIRA, 1982).

$\mathrm{Na}$ Alemanha Friedrich Ratzel ${ }^{3}$ com sua obra, de Antropogeografia - Fundamentos da Aplicação da Geografia à História - continua dando ênfase à influência da natureza sobre o homem, porém insere nas discussões os temas políticos e econômicos. Sua visão geográfica se encontra baseada na concepção orgânica da terra e não considera separadamente os diferentes aspectos da vida no planeta, a relação homem-meio, para ele, é objeto essencial da geografia.

Em contraposição a essa visão, o francês Paul Vidal de La Blache elabora o conceito de gênero de vida, através do possibilismo, concebendo o homem como ser agente que atua sobre o meio e o transforma, "natureza passa a ser encarada como meio possível para a ação humana" (KOSEL, 1998, p.143).

La Blache em seu texto "Des caracters distinctifs de la geografia" deixa evidente a contribuição que a geografia pode oferecer a outras ciências, na medida em que ela "pode trazer para o tesouro comum a aptidão para não dividir o que a natureza juntou, para compreender a correspondência e a correlação dos fatos, seja no meio terrestre que envolve a todos, seja nos meios regionais onde eles se localizam" (La Blache apud Chistofoletti 1985).

\footnotetext{
${ }^{3}$ Capel (1988), em Filososfia y ciencia en la Geografia Contemporanea, aponta Ratzel como o primeiro geógrafo humano, como também o primeiro que identifica geografia com ecologia humana.
} 
Neste momento La Blache também foi influenciado pela corrente historicista que se caracterizava pela reação contra o Positivismo.

Outro francês que concebia a Geografia como ciência da compreensão e reforçava a noção de unidade na ciência é Eliseé Reclus. Para ele a Geografia nasce como ciência para explicar o meio biótico e abiótico.

Essas concepções de bases deterministas e possibilistas assentam-se no principio baconiano de conhecimento da natureza e no seu domínio pelo homem, expressos em Casseti (1991) e Harvey (1993). Essa forma de pensamento encontrou grande respaldo, uma vez, que até os dias atuais, a significação da natureza e do meio-ambiente ainda é de caráter naturalista e utilitarista.

Até o quarto decênio do século XX, as abordagens, pautavam-se no historicismo, tendo como enfoque o caráter nomotéico e ideográfico, porém com uma base extremamente positivista. Neste universo, a crítica se levanta contra a Geografia clássica, algum tempo depois que a mesma já tinha ocorrido em outras ciências. É uma crítica antepositivista e também uma crítica à concepção regional e historicista.

Assim, o pensamento geográfico sofre uma profunda transformação, e são formuladas novas formas de conceber a ciência.

\section{A NATUREZA E A NOVA GEOGRAFIA ${ }^{4}$}

Os anos de 1930-1940 são considerados por diversos autores como um período decisivo nas Ciências Sociais, pois trata-se de um período de crises, tanto econômica quanto social "e estas se vêem estimuladas a dar respostas" (Capel, 1981) e buscam novos métodos de trabalho. Neste contexto surge uma nova forma de orientar as ciências. Com esta nova orientação há o retorno do racionalismo expresso pela probabilidade, pelo neopositivismo e as ciências matemáticas constituem o novo paradigma metodológico.

A Geografia se vê então afetada por essas novas correntes e nesta perspectiva surge o Movimento de Renovação da Geografia que desencadeia o aparecimento da corrente chamada Nova Geografia.

Para Gomes (2000) “a influência do neopositivismo na geografia ocorre progressivamente e é anterior aos anos cinqüenta”. Ele confirma essa afirmação na análise de três autores a saber: com Sauer em 1925 e seu método morfológico; com Hartshorne em 1939,

\footnotetext{
${ }^{4}$ A Nova Geografia ou New Geografy é também chamada de Geografia Teorética e Geografia Quantitativa.
} 
que buscava a generalização através de conceitos claros; e com Schaefer em 1953, com seu artigo intitulado: O excepcionalismo na Geografia.

Os autores que constroem a Nova Geografia afirmam que é necessário descartar os estudos monográficos e regionais do seio da mesma e, a concepção sistêmica deve ser instrumento de sua cosmovisão, assim como o caráter analítico e a valorização dos procedimentos racionalistas.

O significado de natureza na Nova Geografia ou Geografia Quantitativa então é explicada a partir de modelos matemáticos, assim como a relação homem-meio é subsidiada por um verdadeiro aparato científico e tecnológico. A abordagem sistêmica e a modelística começam a ser utilizados na Ciência geográfica com forte ênfase no final dos anos de 1960 e o espaço é categoria chave desta corrente geográfica, como mostra Gomes (2000), a geografia moderna, sob influência desta corrente teórica, produz então uma nova síntese. Nesta versão, a análise espacial constitui o objeto fundante da geografia, e o método sistêmico é aquele com que se pode explicar cientificamente os fenômenos, em suma, a concepção sistêmica deve ser instrumento da nova cosmovisão geográfica.

A Nova Geografia traduz uma visão homem-mundo centrando sua análise no homem, porém de forma descritiva, lógica e matemática, sendo enfocado o distanciamento e a dispersão destes no espaço, não sendo valorizados os grandes problemas ambientais da época. Andrade (1999, p.29), assinala que esse "é um período onde autores como Bunge e Harvey discutiam a natureza e o caráter da Geografia".

Esta corrente começa a mostrar seus limites, e uma série de críticas tanto no plano ideológico quanto epistemológico é evidenciado. Enseja-se o nascimento de uma nova corrente geográfica, e ela nasce intitulada Geografia Radical.

\section{A NATUREZA E A GEOGRAFIA RADICAL ${ }^{5}$}

O início da década de 1970 é fortemente marcado pelo agravamento dos planos ecológicos, urbanos e sociais, associados a uma série de mudanças em suas relações que são evidenciadas pelo processo de globalização em curso e das relações internacionais entre os países que se processam gerando crises ou rupturas. É neste período que as correntes críticas radicais se desenvolverão em oposição ao conhecimento linear e de cunho neopositivista.

\footnotetext{
${ }^{5}$ A Geografia Radical, também é conhecida por Geografia Crítica.
} 
No âmbito da Geografia, outra linha de pensamento se delineia, colocando-se dentro do Movimento de Renovação da Geografia- a corrente radical - que integrará os processos sociais e sua historicidade na sua concepção de mundo. Esta linha radical da Geografia como expressa Capel (1981), “es uma reacción ante las pretenciones de neutralidad de la geografia quantitativa y ante los excessivamente simples modelos elaborados por esta”.

Dentro da corrente radical ressaltamos duas linhas que se destacaram e que conceberão a natureza de forma diferenciada. A primeira linha é a marxista, que tem grande preeminência nas décadas de 1970 e 1980 pela incorporação de suas teorias e conceitos, apesar de várias tendências que o marxismo possui.

Para Quaini (1979, p.43), o marxismo, com seu método materialismo histórico, instaura uma nova relação entre a natureza e o homem. Em Casseti (1991), encontramos a natureza concebida por Marx em dois momentos históricos, a primeira natureza, em que o homem está presente e utiliza a mesma como valor de uso e a segunda natureza que é caracterizada pelo valor de troca.

Dessa forma temos em Marx a natureza como produto social, e a relação homem-meio mediada pelo trabalho. Assim a Geografia de inspiração marxista compreende que o homem é uma parte da natureza e busca a reflexão das ações sociais.

A segunda linha de pensamento é a Geografia Humanística, de cunho antepositivista e contrária a racionalização e quantificação na ciência. É uma Geografia que destaca os aspectos humanos (valores, ações, significados), dando ênfase a experiência pessoal em oposição ao enfoque mecanicista e abstrato do homem, confirmado em Capel (1981), Gomes (2000) Tuan (1982).

O existencialismo, a fenomenologia e a hermenêutica constituem a base filosófica da Geografia Humanística que mesmo com suas particularidades próprias partilham da centralidade do homem, bem como da subjetividade presente nas ações humanas.

No que concerne à relação homem-natureza, ocorre um redimensionamento desta relação, pois a "Geografia humanística preocupada com a morada do homem, e qualquer escala, tem procurado explorar a influência da natureza e, insistentemente enfocar as intervenções humanas no espaço em busca incessante da felicidade e da promoção da boa vida" (MELLO, 1993).

Com base no viés fenomenológico, na geografia existe a compreensão de que o homem não pode ser considerado separado do ambiente, e deve haver uma recuperação das distorções 
científicas produzidas sobre ele, ou seja, "o humanistas não nega as perspectivas científicas sobre o homem, trabalha sobre elas". ${ }^{6}$ A partir desta afirmação o ambiente é concebido em sua totalidade sendo construído historicamente e culturalmente.

\section{MODERNIDADE, PÓS-MODERNIDADE E QUESTÃO AMBIENTAL}

Atualmente, vivemos em uma época de rápidas transformações que afetam a humanidade e a vida no planeta. Essas transformações decorrem de um longo processo histórico, que tem no advento da Revolução Industrial e no avanço do capitalismo as bases de seu crescimento, e o século XX como ápice desse crescimento.

Tudo isso se tornou possível em função do processo de globalização que tem como fundamento o desenvolvimento da técnica, como afirma Santos (2002,p.192), "com a emergência do período técnico-científico, no imediato pós-guerra, o respectivo sistema técnico se torna comum a todas as civilizações, todas as culturas, todos os sistemas políticos, todos os continentes e lugares".

Porém, esse ideário de desenvolvimento começa a ser formulado no final do século XVIII, denominado o Século das Luzes. Neste século observa-se uma ruptura com o conhecimento precedente, passando a vigorar um conhecimento ancorado em um novo racionalismo. A ciência adquire status de moderna, firmando-se de fato no século XIX. Esse momento será designado por Modernidade.

As características básicas da Modernidade fundamentam-se na objetividade, na razão, na generalização, no saber especializado. As ciências incorporam essas características na construção do conhecimento e consequentemente toda a sociedade é afetada por esse processo. Para Haesbaert (1990) a modernidade, então, é concebida antes de mais nada como a era da racionalidade, da tecnologia, da tecnocracia e, portanto, do "controle social".

No percurso da modernidade observamos o surgimento de uma crise complexa e com diferentes nuances que segundo Buarque (apud Sato, 1997),

É fruto dos "sustos" que a modernidade tem levado: do avanço tecnológico, do fracasso utópico, da integração mundial (mas dos países desintegrados e, portanto, da desintegração dos homens), do limite ecológico da Terra, da queda, das bandeiras (particularmente da instituição familiar), da crise ecológica, da dobra da esquina técnica (ou da capacidade imaginativa do ser humano) e, finalmente, o descobrimento da ética.

\footnotetext{
${ }^{6}$ TUAN,Yi-Fu. Geografia Humanista. In: Christofolleti, A. Perspectiva da Geografia.
} 
Para Harvey (1993), “a modernidade, por conseguinte, não apenas envolve uma implacável ruptura com todas e quaisquer precedentes, como é caracterizada por um interminável processo de rupturas e fragmentações internas inerentes”.

Frente à crise que se evidencia, sendo fortemente marcada nos meados de 1970, e chama-se crise do paradigma da modernidade, já se vislumbra tendências críticas que apontam rumos diferentes e recebem designações diferenciadas. Harvey (1993) adota o termo condição pós-moderna, Gomes (2000) por pós-modernidade, Morin (2000) paradigma da complexidade e Souza Santos (2000) paradigma emergente.

A tendência pós-moderna fundamenta-se numa postura de reorientação das ciências para o desenvolvimento de um conhecimento que provoque ruptura com os enfoques neopositivistas e assinala ênfase no humano, valorizando a cultura, a subjetividade e também busca a superação da dicotomia entre sujeito e objeto.

Para Monteiro (1995) o "que se designa como pós-moderno (no campo das artes) pósindustrial (no campo da economia) não são soluções a caracterizar a própria mudança, mas tentativa de desconstruções e Elaboração de novas tendências e estratégias em direção a ela".

Na compreensão sobre o pós-moderno Harvey (1993) aponta alguns traços da literatura, do cinema, da arquitetura entre outros, que são relevantes para entender este processo. Para ele a aceitação do efêmero, do fragmentário, do descontínuo é o fato mais acentuado no pósmodernismo.

A evolução do pensamento geográfico ao observarmos a partir do conceito de natureza enquanto conhecimento científico, não ficou isenta às mudanças inerentes a modernidade ou a pós-modernidade, uma vez que suas correntes de pensamento apoiam-se em característica, que em determinado momento, estão no contexto da modernidade e em outros estão no contexto da pós-modernidade segundo alguns autores.

No campo ambiental o embate da modernidade e pós-modernidade é claramente visível, e a análise da questão ambiental recebe uma diversidade de enfoque e direcionamento. Podemos observar que no chamado contexto da modernidade, a abordagem ambiental é extremamente de caráter utilitarista, fincada em um processo em que a relação homem-meio é compreendida de forma separada e o homem é um ser oposto a natureza. Na natureza o homem realiza as transformações necessárias a sua sobrevivência, tendo-a como um recurso vital.

É no período considerado como modernidade que se evidencia uma grande crise ecológica imposta através dos problemas ambientais, das catástrofes, da sustentabilidade, da pobreza, entre outros. Aparecem nesse universo os movimentos ecológicos em oposição à 
modernidade. Benko (1999, p. 205-206), considera três grandes correntes ecológicas que têm em comum a crítica a modernidade:

\begin{abstract}
Corrente de direita (mesmo de extrema direita) que se reclama um passado perdido: o mito quase romântico da idade do ouro, da diversidade cultural, da sociedade rural (terroir), do homem vivendo em harmonia com a natureza. Corrente de esquerda (extrema esquerda)...que reivindicam inspiração em Felix Guattari e em seu livro as três ecologias (1989). Facea este universo capitalista, unidimensional, universalizante, já denunciado por Marcuse (1964), é preciso resingularizar-se os indivíduos e os modos de vida...A terceira corrente na nebulosa ecológica faz uma crítica interna da democracia, e advoga utilizar a ciência para opor-se diretamente aos efeitos negativos da ciência e da técnica. A democracia deve integrar a todos os níveis de decisão. Seu discurso político é mudo e recoberto pelas duas outras correntes.
\end{abstract}

No que concerne aos ditos pós-modernos a problemática ambiental é abordada a partir de uma visão holística, tendo a ética como princípio básico sendo a sociedade sujeito e não apenas agente e a dimensão social deve ser enfocada nos problemas ambientais.

Para Orr (1992 apud Sato 1997) no seu discurso pós-moderno "considera a importância de resgatar as experiências na infância, o despertar para o sentido do lugar, a biofilia e finalmente, o patriotismo necessário para movermos em direção à biofilia com amor e estabilidade ecológica para conservar nossas casas".

\title{
GEOGRAFIA E EDUCAÇÃO AMBIENTAL
}

A abordagem da temática ambiental, no centro das discussões da geografia, tem promovido o engajamento de muitos geógrafos na contribuição e busca de possibilidades que promovam uma reflexão sobre o mundo que vivemos e dos conflitos que vivenciamos. Alguns autores salientam que a construção de um pensamento ambiental na geografia deve ultrapassar a visão dicotomizadora desta ciência, a dualidade entre geografia física e geografia humana.

Nas últimas décadas, a perspectiva ambiental toma corpo na geografia, e vem sendo construída no seio da mesma a vertente ambiental denominada de geografia socioambiental.

Esta vertente socioambiental não deve rogar-se como a mais importante dentro da ciência geográfica, mas pode resgatar sua unidade, sendo que a mesma configura-se numa perspectiva de entender seu objeto de estudo de forma holística e interdisciplinar. Está ancorado, "na concepção de que talvez o maior ponto de relevância epistemológica para a geografia esteja na atitude fenomenológica de não considerar a natureza (matéria da 
experiência) nem o homem (corpo que percebe) como fundantes” Monteiro (apud Mendonça, 1998).

A relação homem-natureza, na geografia socioambiental, é considerada de maneira totalizante e não passiva, sendo direcionado olhares em que o social não é desconsiderado nesta relação.

De acordo com essa concepção nos remetemos ao item 1 deste artigo em que são relacionados os diversos significados e modos de conceber a natureza e a relação homemmeio através da evolução do pensamento geográfico. Para nós o entendimento dessas concepções constitui um caminho para o trabalho no campo da educação ambiental a partir da Geografia. Assim aponta Cavalcanti (2001, p. 116) "as diferentes representações sobre natureza, podem desencadear um processo de construção ou socioconstrução de conceitos, análises, referentes à questão ambiental e à sociedade contemporânea".

É preciso salientar que um estudo no campo ambiental, a partir das concepções e representações de natureza e do meio ambiente, envolve a compreensão de sua dinâmica, de sua complexidade e da reformulação paradigmática por qual se evidencia na atualidade.

Esse viés do estudo da natureza pela Geografia integrando com a Educação Ambiental não deve ser abordado de forma reducionista, ao contrário, deve ser superado e ser estabelecido um diálogo. Essa preocupação atende aos princípios diretores para Educação Ambiental na Conferência de Tbilisi, que enfoca em suas recomendações a perspectiva holística e interdisciplinar da mesma. Atualmente, a visão holística também é defendida por muitos autores com o objetivo de perceber os problemas ambientais na chamada crise da modernidade.

Com base nesse entendimento pode-se aferir que a geografia possui capilaridade suficiente para contribuir com o desenvolvimento da educação ambiental.

A educação Ambiental configura-se nas últimas décadas como um elemento decisivo para o entendimento e o repensar da existência humana. Foi com a conferência de Tibilisi que a Educação ambiental se expandiu, assim sendo implantada em diversos países, mesmo com diferentes nuances.

A definição formulada para a Educação Ambiental na Conferência de Tibilisi consideraa como um processo de construção de valores em que os indivíduos devem compreender a complexidade do meio ambiente tanto natural, quanto ao criado pelo homem, para que adquiram conhecimentos e habilidades e de forma responsável tomem decisões para a resolução dos problemas ambientais. 
Com relação aos valores que estão contidos na definição da Educação Ambiental de Tibilisi, Grun (1996, p.22), aponta: “a educação ambiental deve ser permeada por uma discussão e reapropriação de certos valores; valores estes que muitas vezes não estão no nível mais imediato da consciência, mas encontram-se profundamente reprimidos ou recalcados através de um longo processo histórico".

A discussão sobre Educação Ambiental, seus conceitos, modalidades e metodologias não se esgota e assume variadas formas e modelos. O debate em torno da representação da natureza e do meio ambiente é um exemplo dessa complexidade.

Em pesquisa realizada sobre educação ambiental e o ensino de geografia Alberto (2002), tentou perceber o contributo da educação geográfica na EA (designadamente a sua interligação na disciplina de Geografia, a nível do secundário), e a partir daí considera que uma visão considerada integradora da realidade por parte dos professores que ensinam Geografia (diferente da tendência geral apresentada pela pesquisa) deve incluir elementos envolvidos na construção do conhecimento da comunidade e de suas relações com a sociedade global.

Também através de pesquisas no que se refere às fontes de informação sobre educação ambiental ou sobre as questões ambientais, em pesquisa realizada com os professores de Geografia sobre educação ambiental Bortolozzi e Perez Filho (2000) assinalam que:

Predomina então um acompanhamento próprio dos meios de difusão do sistema de comunicação social, ou seja, meios de comunicação de massa (mass media), sendo que o sistema de educação formal deixa a desejar, resultando na própria falta de consciência ambiental e na inadequada formação acadêmica, apresentadas pela maioria dos professores pesquisados, pois eles não estão acompanhando a questão ambiental pelos mecanismos que deveriam ser próprios da educação em todos os níveis, principalmente pela difusão, por exemplo, por meio de textos, livros paradidáticos, cursos, palestras, simpósios encontros e congressos. Mais grave ainda torna-se o quadro, ao considerar-se que na imprensa escrita e falada predominam, principalmente na TV, os temas amplos envolvendo meio ambiente, ecologia, equilíbrio ecológico, extinção de espécies que, raramente apresentando uma abordagem socioambiental, eliminam a explicação sobre as causas dos problemas.

Assim, cremos que pensar a geografia e a educação ambiental possibilita alternativas no ensino de geografia como também através da espacialização dos fenômenos e da abrangência da análise geográfica é possível o ensino de uma educação ambiental que considera a relação natureza e sociedade complexa e conflituosa, mas que uma não exclua a outra. 


\section{CONSIDERAÇÕES FINAIS}

A análise da evolução do pensamento geográfico, através do significado da natureza e da relação homem-meio, deixa evidente que há uma busca de novos caminhos para a ciência geográfica e que nas corrrentes geográficas não há linearidade, e, mesmo com o surgiemnto de uma nova teoria, de um novo arcabouço metodológico outras teorias continuam existindo e influenciando-a.

Assim cada teoria e cada corrente apresentam uma contriuição, uma formulação aos elementos chaves da geografia, e fazem-na dentro do contexto da modernidade e da pósmodernidade.

É na atenção conferida à discussão da modernidade e do pós-moderno que levantamos o questionamento se estamos de fato em um período pós-moderno, ou, o que ora se evidencia são aspectos de uma modernidade inacabada. Sem nos omitirmos dessa discussão e do caráter de neutralidade com relação à mesma, necessitamos nos aproximar da diversidade e da pluralidade teórica e da busca de saberes comprometidods e não alienantes. Assim confifrma Benko (1999, p.211) “os geográfos não poderão escapar aos jogos do discurso: moderno ou pós-moderno".

O debate ambiental subjaz à discussão da modernidade e pós-modernidade. Os desdobrametos e formas de pensar o ambiental bem como a educação Ambiental perpassa esses dois “modos (os fundamentos) característicos de civilização” Benko (1999, p.187).

A educação ambiental emerge como possibilidade de enfrentar os desafios que hoje são colocados à sociedade. Porém, a própria Educação Ambiental é carregada de desafios que Tristão aponta na sociedade do conhecimento: a multiplicidade de visões, a superação da visão do especialista, a superação da pedagogia das certezas e a superação da lógica da exclusão.

Acreditamos que compreendendo o mosaico que se insere no âmbito ambiental, perceberemos uma nova dimensão na educação ambeintal.

E a educação geográfica tem uma contribuição importante na educação ambiental, na sensibilização dos alunos sobre o impacto do seu próprio comportamento, e suas atitudes, e é uma ciência que possui uma identidade marcante pois enquanto ciência da natureza e da sociedade reflete sobre a natureza, o meio ambiente e a sociedade. "A questão ambiental pertinente também à geografia, não é sua exclusividade. Sua complexidade exige conjunção 
de olhares, dialógica e a superação da análise de objetos puros (específicos)”(SUERTEGARAY, 2006, p. 27).

\section{REFERÊNCIAS BIBLIOGRÁFICAS}

ALBERTO, Alzira Filipe. O contributo da educação geográfica na educação ambiental. O caso da geografia no ensino secundário.

ANDRADE, M.C. A construção da geografia brasileira. RA'EGA- O espaço geográfico em análise. Curutibsa, n. 3, ano III, ed. Da UFPR, 1999,p.19-34.

BENKO, G. Modernidade, pós-modernidade e Ciências sociais. Revista do departamento de Geografia, AGB-SP, n.13, 1999, p.187-213.

BORTOLOZZI, A.; PEREZ FILHO, A. Diagnóstico da educação ambiental no ensino de geografia. Cadernos de Pesquisa, n. ${ }^{\circ} 109$, p. 145-171, março/2000.

CASSETI, V. A essência da questão ambiental. Boletim Goiano de Geografia. Universidade federal de Goiás, v.111 (1), jan./dez. 1991, p.1-23.

CLAVAL, P. A revolução pós-funcionalista e as concepções atuais da geografia. In: MENDONÇA, F.; KOSEL, S. (orgs.). Elementos da Epistemologia da Geografia Contemporânea. Ed. Da UFPR, 2002, p. 11-43.

CAPEL, H. Filosofia y ciência en la Geografia contemporânea. Barcelona, Barcanova, 1981.

CAVALCANTI, L. de S. Geografia, escola e construção de conhecimento. Campinas: SP, Papirus, 2001.

GOMES, P. C. da C. Geografia e modernidade. RJ: Bertrand Brasil, 2000.

GRUN, M. Ética e Educação Ambiental - a conexão necessária. SP: Papirus, 1996.

HAESBAERT, R. da C. Filosofia, Geografia e Crise da modernidade. Terra Livre. Revista da AGB, n.7, SP, 1990, p. 63-92.

HARVEY, D. Condição pós-moderna. SP:Loyola,1993.

KOSEL, S. Ensinar geografia no terceiro milênio. RA'EGA. O espaço geográfico em análise. Curitiba/UFPR, n.2, 1998, p. $141-152$.

MADRUGA, A. Bases para o estudo do "Determinismo geográfico" e da "Geografia quantitativa" - o positivismo e a teoria dos sistemas. Geosul. Revista do Departamento de Geociências. Florianópolis: ed. UFSC, v. 1, n.1 (1 sem. 1986), p.88-101. 
MELLO, J. B. F. de. A humanização da natureza - uma odisséia para a (re)conquista do paraíso. Geografia e Questão ambiental. In: MESQUITA, O. V; SILVA, S.T. (coords.) RJ:IBGE, Departamento de Geografia, 1993, 31-40.

MENDONÇA, F. Dualidade e dicotomia na Geografia moderna. RA'EGA, o espaço geográfico em análise. Curitiba: UFPR, ano 2, n. 2, 1988, p. 153-165.

MENDONÇA, F. Geografia socioambiental. In: MENDONÇA, F; KOSEL, S. (orgs.) Elementos da epistemologia da Geografia contemporânea. UFPR, 2002.

MOREIRA, R. O que é geografia. SP: Brasiliense, 1982.

QUAINI, M. Marxismo e Geografia. RJ: Paz e Terra, 1979.

SANTOS, B. de S. A crítica da razão indolente: contra o desperdício da experiência. SP: Cortez, 2000.

SANTOS, M. A natureza do espaço - técnica e tempo. Razão e emoção. SP: EDUSP, 2002.

SATO, M. Educação para o Ambiente Amazônico. Tese de doutoramento. Centro de Ciências Biológicas e da Saúde. Universidade federal de São Carlos. São Carlos: SP. 1997.

SUERTEGARAY, D. M. A. Questão ambiental: produção e subordinação da natureza. In: SILVA, J. B. da. et al. Panorama da Geografia Brasileira. SP: Annablume, 2006.

TRISTÃO, M. As dimensões e os desafios da educação ambiental na sociedade do conhecimento. In: RUSCHEINSKY, A. Educação Ambiental - abordagens múltiplas. Porto Alegre: Artmed, 2002.

TUAN, Yi-Fu. Geografia Humanística. In: CHRISTOFOLETTI, A. Perspectivas da Geografia. SP: Difel, 1982. 